\title{
A Review on Clinical Outcomes of Pancreaticoduodenectomy in Octogenarian Patients
}

\author{
Danilo Coco', Silvana Leanza² \\ ${ }^{1}$ Department of General Surgery, Ospedali Riuniti Marche Nord, Pesaro (PU); ${ }^{2}$ Department of General Surgery, Carlo Urbani Hospital, Jesy (AN), Italy
}

\begin{abstract}
Management of malignant diseases in elderly patients has been a global clinical issue because of increased life expectancy worldwide. Currently, pancreatic adenocarcinoma mainly occurs after 60 years of age, and its prognosis remains poor despite modest improvements in recent decades. Surgical resection is the only potentially curative treatment for pancreatic cancer. Resection of the pancreas, either by pancreaticoduodenectomy (PD) or laparoscopic pancreaticoduodenectomy (LPD) is a complex surgical procedure with a high rate of morbidity and mortality. However, mortality rates after pancreatic surgery have dropped to less than $2-5 \%$ at experienced centers. Whereas, complication rates are high, reaching at least $30 \%$ in many centers. Mortality also increases proportionally with age viz. $6.7 \%$ of patients aged $65-69$ years, $9.3 \%$ of patients aged $70-79$ years, and $15.5 \%$ of patients aged 80 years or older. The present review article delineates clinical outcomes along with safety, morbidity and mortality after PD or LPD in elderly, especially in octogenarian patients.
\end{abstract}

Korean J Pancreas Biliary Tract 2021;26(2):105-110

Keywords: Aged, 80 and over, Pancreaticoduodenectomy, Outcomes assessment, Morbidity, Mortality

\author{
Received Feb. 5, 2021 \\ Revised Mar. 16, 2021 \\ Accepted Mar. 17, 2021
}

Corresponding author: Danilo Coco

Department of General Surgery, Ospedali Riuniti

Marche Nord, Viale Trieste, 391, 61121 Pesaro (PU), Italy

Tel. +39-3400546021 Fax. +39-3400546021

E-mail; webcostruction@msn.com

ORCID: https://orcid.org/0000-0002-5839-1767

This is an Open Access article distributed under the terms of the Creative Commons Attribution Non-Commercial License (http:// creativecommons org/licenses/by-nc/3.0/) which permits unrestricted non-commercial use, distribution, and reproduction in any medium, provided the original work is properly cited.

Copyright $\odot 2021$ by The Korean Journal of Pancreas and Biliary Tract

\section{INTRODUCTION}

Pancreatic cancer is one of the most malignant diseases and its prognosis is dismal. In contrast to the steady increase in survival for most cancers, advances have been slow for pancreatic cancers, for which the 5 -year relative survival is currently $8 \%$. This low survival rate for which 5 -year survival is $2 \%$ is partly due to the high rate of an advanced stage at the time of diagnosis. ${ }^{1}$ Only complete resection of the lesion provides a chance at cure. However, the survival rates following surgery for pancreatic cancer remain poor and have improved only marginally in recent decades. $^{2,3}$

In elderly patients, pancreatic cancer is associated with higher perioperative mortality and morbidity rates, higher requirement of an intensive care unit stays, increased length of hospital stay, and higher rates of hospital readmission after pancreatectomy. ${ }^{4-8}$ Advanced age is a risk factor for pancreatic adenocarcinoma. The incidence of pancreatic cancer is 29 per 100,000 in patients younger than 65 years compared with 91 per 100,000 in patients 80 to 84 years old. ${ }^{9}$

Surgical resection is the only potentially curative treatment for pancreatic cancer. Unfortunately, only $15 \%$ to $20 \%$ patients are candidates for pancreatectomy due to the late presentation of symptoms and/or detection of the disease.$^{10-12}$ Furthermore, the rate of resectability diminishes with age. Some authors reported that $40 \%$ of patients between the ages of $66-70$ years are candidates for a pancreatectomy, but by the age of 85 years, only $7 \%$ are eligible candidates. ${ }^{13,14}$

Pancreaticoduodenectomy (PD) is the surgical choice with acceptable morbidity and mortality in patients over elderly aged 
population. ${ }^{15-19}$ With these viewpoints the present review article was focussed to delineate clinical outcomes along with safety, morbidity and mortality after Pancreaticoduodenectomy in elderly, especially in octogenarian patients.

\section{MAIN BODY}

\section{Characteristics of elderly and therapeutic decisions}

The population of western countries is aging, and because the incidence of cancer increases with age, the population of patients with cancer is growing. More than $50 \%$ of all newly diagnosed patients with cancer are older than 60 years, and more than one third are over the age of $70 .^{20}$

By the year $2030,70 \%$ of all malignancies and $85 \%$ of all cancerrelated deaths are expected to occur in individuals aged 65 years or older, and therefore, older people will likely represent the prototypical cancer patient in the future. ${ }^{21}$ Age is an important risk factor for the development of pancreatic cancer. Whereas the overall incidence rate of pancreatic cancer for all ages is $11.7 \%$, the incidence rate among individuals older than 65 years and older than 80 years is $66.4 \%$ and up to as many as $91.1 \%$ respectively.

Several studies have shown that older cancer patients are often undertreated and have poorer outcomes compared with younger individuals. ${ }^{23,24}$ This outcome may be due to the less aggressive treatment of elderly patients. Focusing on pancreatic cancer, some studies have shown that nearly half of all elderly patients did not receive any treatment for locoregional pancreatic cancer. Moreover, only $11 \%$ received a multimodal therapy (surgery $+/$ chemoradiotherapy). ${ }^{25}$

Because elderly patients are a heterogeneous group, routine individual assessments of frailty and fitness are required. Such assessments may guide treatment decisions through evaluations of the balance of benefits and harms associated with performing or omitting specific oncologic interventions.

\section{1) Patient selection criteria}

PD treatment outcomes in elderly patients have been reported to be acceptable, but the patient selection criteria are not clear. To elucidate the importance of PD in octogenarians in particular, Shiozawa et al. ${ }^{26}$ recommended five patients eligibility criteria for elderly patients based on preoperative cardiac and pulmonary function, nutritional status, daily activity status, and psychological independence status. These PD eligibility criteria for elderly patients set in this study may be helpful when uncertainties arise regarding the selection of $\mathrm{PD}$. The patient eligibility criteria are as follows:

1. Cardiac function: ejection fraction, measured by Doppler echocardiography: at least 40.

2. Pulmonary function: forced expiratory volume in 1 second (FEV 1.0\%), as shown by a spirogram: at least $50 \%$.

3. Nutritional status: serum albumin level: at least $3.0 \mathrm{~g} / \mathrm{dL}$.

4. Daily activity status: Karnofsky performance status: at least $80 \%$.

5. Psychological independence status: capable of self-determination with respect to surgery

Simple prolongation of biological life is not the sole objective of PD for elderly patients, and decisions must be made from the point of view of prolonging healthy life. In other words, in addition to the aim of radical treatment by surgery, the hope is for surgery that does not reduce the patent's postoperative quality of life. In this context, the PD eligibility criteria for elderly patients set in the of Shiozawa et al. ${ }^{26}$ would be helpful when uncertainties arise regarding the selection of PD.

\section{2) Pancreaticoduodenectomy (PD)}

PD is highly invasive operation and literature reports revealed that PD was safe and feasible for the older patients in the aspect of short-term outcomes. ${ }^{27-31}$ In a retrospective cohort study conducted by Kang et al. ${ }^{32}$ on to compare the postoperative shortand long-term outcomes of PD in between older patients and younger patients. Among total of 1,249 study subjects; 168 subjects were included in the older group. The findings of this study revealed that postoperative complication rates, duration of postoperative hospital stay, and 30-day mortality were comparable between the two groups, although the admission rate of intensive care unit postoperatively was higher in the older adult group ( $20.8 \%$ vs. $10.5 \%, p<0.001)$. In terms of long-term outcomes, 5 -year overall survival rate was lower in the older group ( $23.4 \%$ vs. 
$41.8 \%, p<0.001$ ), and 5-year cumulative recurrence rate was higher in the older group without statistical significance (63.9\% vs. $57.9 \%, p=0.095)$. However, there were no statistical differences of cumulative recurrence in pancreatic cancer patients $(81.5 \%$ vs. $82.5 \%, p=0.805)$. Hence, Kang et al. ${ }^{32}$ concluded that PD for periampullary cancer is a safe and feasible treatment in the older patients.

The single-institution retrospective studies that analysed peri-operative outcomes of pancreatic resections in octogenarians were as summarized in Table 1. ${ }^{9,33-35}$ The patient population analysed in those reports was very heterogeneous, as indications for surgery included different types of pancreatic malignancies and peri-ampullary tumours as well as benign pancreatic diseases. Rates of perioperative mortality and overall morbidity for octogenarians appeared similar to younger patients.

Melis et al. ${ }^{35}$ conducted original research study on evaluation of the safety of a PD in patients older than 80 years. The method adopted by authors in their study was differences in two groups of patients (Group Y, $<80$ and Group O, $\geq 80$ year-old) who underwent a PD for pancreatic adenocarcinoma were analysed. Study end-points were length of postoperative stay, overall morbidity, 30-day mortality and overall survival. The results revealed that Octogenarians had worse Eastern Cooperative Oncology Group Performance Status (PS $\geq 1$ : 90\% vs. 51\%) and American Society of Anesthesiology score (>2: 71\% vs. 47\%). The two groups were similar in underlying co-morbidities, operative time, rates of portal vein resection, intraoperative complications, blood loss, pathological stage and status of resection margins. Octogenarians had a longer post-operative stay (20 days vs. 14 days) and higher overall morbidity (68\% vs. 44\%). There was a single death in each group. At a median follow-up of 13 months' median survival appeared similar in both the groups (17 months vs. 13 months). Hence, based on the findings of the present study Melis et al. ${ }^{35}$ recommended that PD can be offered to carefully selected octogenarians since 30-day mortality and survival are similar to those observed in younger patients. Whereas, A recent metaanalysis paper reported by Kim et al. ${ }^{36}$ included total of 18 studies for evaluation. The findings revealed that Octogenarian or older populations had significantly higher 30-day post-operative mortality rate (OR 2.22, 95\% CI 1.48-3.31, $p<0.001)$ and length of hospital stay (OR 2.23, 95\% CI 1.36-3.10, $p<0.001$ ). The overall post-operative complication rate was higher in the older group compared to the younger population (OR 1.51, 95\% CI 1.25-1.83, $p<0.001)$. Elderly patients were more likely to develop pneumonia (OR 1.72, 95\% CI 1.39-2.13, $p<0.001)$ and experience delayed gastric emptying (OR 1.77, 95\% CI 1.35-2.31, $p<0.001$ ). The incidence of post-operative pancreatic fistula and bile leak were not significantly different between the groups. Rehabilitation and home nursing care services was also more frequently required by the older patient group at the time of hospital discharge. Based on these findings Kim et al. ${ }^{36}$ concluded that reported that patients aged 80 years and older have approximately double the risk of 30 -day postoperative mortality and 50\% increased rate of complications following $\mathrm{PD}$, and hence careful patient selection is

Table 1. Summary of peri-operative outcomes of pancreatic resections in octogenarians

\begin{tabular}{|c|c|c|c|c|c|c|c|}
\hline Indications for surgery & $\begin{array}{l}\text { Operations } \\
\text { performed }\end{array}$ & Age & $\mathrm{N}$ & $\begin{array}{c}\text { Overall } \\
\text { morbidity (\%) }\end{array}$ & $\begin{array}{l}\text { Mortality } \\
(\%)\end{array}$ & $\begin{array}{c}\text { OS } \\
\text { (months) }\end{array}$ & Study \\
\hline \multirow{2}{*}{$\begin{array}{l}\text { Pancreatic and peri-ampullary } \\
\text { malignancy }\end{array}$} & \multirow[t]{2}{*}{ PD } & $70-79$ & 82 & 56.00 & 12.00 & 16.00 & \multirow[t]{2}{*}{ Chen et al. ${ }^{33}$ (2003) } \\
\hline & & $80-89$ & 16 & 51.00 & 13.00 & 17.60 & \\
\hline \multirow[t]{3}{*}{ Benign and malignant pathology } & \multirow[t]{3}{*}{ PD } & $<80$ & 2,491 & 41.60 & 1.70 & 18 & \multirow[t]{3}{*}{ Makary et al..$^{34}(2006$} \\
\hline & & $80-89$ & 197 & 52.80 & 4.10 & 11 & \\
\hline & & $\geq 90$ & 10 & 50.00 & 0.00 & 15 & \\
\hline \multirow[t]{2}{*}{ Benign and malignant pathology } & \multirow[t]{2}{*}{ PD } & $<80$ & 703 & 51.10 & 3.80 & 18.10 & \multirow[t]{2}{*}{ Lee et al. $^{9}(2010)$} \\
\hline & & $\geq 80$ & 74 & 47.30 & 5.40 & 11.60 & \\
\hline \multirow[t]{2}{*}{ Pancreatic adenocarcinoma } & \multirow[t]{2}{*}{ PD } & $<80$ & 175 & 44.00 & 0.57 & 13 & \multirow[t]{2}{*}{ Melis et al. ${ }^{35}$ (2012) } \\
\hline & & $\geq 80$ & 25 & 68.00 & 4.00 & 17 & \\
\hline
\end{tabular}

OS, overall survival; PD, pancreaticoduodenectomy. 
required when offering surgery in this age group. ${ }^{36}$

\section{3) Laparoscopic pancreaticoduodenectomy (LPD)}

LPD was first introduced in $1994^{37}$ in recent years; this approach has been shown to be safe and feasible when performed by experienced surgeons in centers with high volumes of cases. ${ }^{38}$ Laparoscopic surgery bestows several advantages when compared to open surgery in elderly patients undergoing pancreatoduodenectomy (PD). ${ }^{39-41}$ In addition, both have similar oncological results. ${ }^{39,41,42}$ Laparoscopic surgery in a number of studies, has been shown to result in less postoperative pain, fewer wound complications, shorter hospital stays, decreased pancreatic fistula rates, and decreased surgical morbidity and mortality. ${ }^{39,43,44}$ However, longer operation times and higher incidences of organ injury. ${ }^{45-47}$ are of particular concern when considering LPD surgery for elderly patients. ${ }^{48}$ One retrospective analysis of robot-assisted PDs concluded that the procedure can be performed safely in elderly patients with mortality, morbidity, and outcomes comparable to those in younger patients. ${ }^{49}$ Beltrame et al. ${ }^{50}$ showed that outcomes after pancreatectomy were not markedly different in octogenarians than in younger patients, ${ }^{50}$ and Furthermore, Yamashita et al. ${ }^{51}$ found no statistically significant difference in the mortality rate or overall morbidity rate in patients undergoing PD for periampullary tumors above and below the age of 75 .

In a very recently published systematic review and meta-analysis study conducted by Hendi et al. ${ }^{52}$ compared the risk of LPD in elderly and non-elderly patients since past articles have reported that elderly patients undergoing LPD are at an increased risk compared to younger patients. The findings of this study revealed that elderly patients who underwent LPD in this study had good overall outcomes after LPD that were similar to young patients. The perioperative and long-term outcomes of LPD are not worse. Rates of ICU admission and hospital stays increased in elderly patients undergoing LPD when compared with nonelderly ones. LPD could be performed on elderly patients with similar outcomes as younger patients. Therefore, age itself should not be a contraindication for LPD for pancreatic cancer, but it was suggested that elderly patients with comorbidities should be more stringently selected for surgery. ${ }^{52}$

\section{CONCLUSIONS}

In conclusion, age should not be the determining factor in decisions regarding the best approach. An integral evaluation of the patient in accordance with appropriate tools should be conducted. Furthermore, the patient eligibility criterions recommendations could be practiced in order increase postoperative quality of life. PD or LPD could be offered for pancreatic resections with better clinical outcomes in Octogenarians diagnosed with periampullary cancer and benign pancreatic diseases. Octogenarians undergoing PD have approximately double the risk and 50\% increased rate of complications following PD, and hence careful patient selection is required when offering surgery in this age group.

\section{Conflicts of Interest}

The authors have no financial conflicts of interest.

\section{Acknowledgments}

Thanks to Silvana Leanza for the collaboration.

\section{REFERENCES}

1. Siegel RL, Miller KD, Fedewa SA, et al. Colorectal cancer statistics, 2017. CA Cancer J Clin 2017:6:177-193.

2. Gleisner AL, Spolverato G, Ejaz A, Pawlik TM. Time-related changes in the prognostic significance of the total number of examined lymph nodes in node-negative pancreatic head cancer. J Surg Oncol 2014;110:858-863.

3. Winter JM, Brennan MF, Tang LH, et al. Survival after resection of pancreatic adenocarcinoma: results from a single institution over three decades. Ann Surg Oncol 2012;19:169-175.

4. Lee DY, Schwartz JA, Wexelman B, Kirchoff D, Yang KC, Attiyeh F. Outcomes of pancreaticoduodenectomy for pancreatic malignancy in octogenarians: an American College of Surgeons national surgical quality improvement program analysis. Am J Surg 2014;207:540-548.

5. Lightner AM, Glasgow RE, Jordan $T H$, et al. Pancreatic resection in the elderly. J Am Coll Surg 2004;198:697-706.

6. Bathe OF, Levi $D$, Caldera $H$, et al. Radical resection of periampullary tumors in the elderly: evaluation of long-term results. World I Surg 2000;24:353-358.

7. Casadei $R$, Ricci $C$, Lazzarini $E$, et al. Pancreatic resection in patients 80 years or older: a meta-analysis and systematic review. Pancreas 
2014:43:1208-1218.

8. Mauriello C, Polistena A, Gambardella C, et al. Pancreatic stump closure after pancreatoduodenectomy in elderly patients: a retrospective clinical study. Aging Clin Exp Res 2017;29:35-40.

9. Lee MK, Dinorcia J, Reavey PL, et al. Pancreaticoduodenectomy can be performed safely in patients aged 80 years and older. J Gastrointest Surg 2010;14:1838-1846.

10. Riall TS. What is the effect of age on pancreatic resection?. Adv Surg 2009:43:233-249.

11. Riall TS, Reddy DM, Nealon WH, Goodwin JS. The effect of age on short-term outcomes after pancreatic resection: a population-based study. Ann Surg 2008;248:459-467.

12. Riall TS, Sheffield KM, Kuo YF, Townsend CM Jr, Goodwin JS. Resection benefits older adults with locoregional pancreatic cancer despite greater short-term morbidity and mortality. J Am Geriatr Soc 2011;59:647-654.

13. Sohn TA, Yeo CJ, Cameron JL, et al. Should pancreaticoduodenectomy be performed in octogenarians?. J Gastrointest Surg 1998;2:207-216.

14. Meguid RA, Ahuja N, Chang DC. What constitutes a "high-volume" hospital for pancreatic resection?. J Am Coll Surg 2008;206:622.e1622.e6229.

15. Scurtu R, Bachellier P, Oussoultzoglou E, Rosso E, Maroni R, Jaeck D. Outcome after pancreaticoduodenectomy for cancer in elderly patients. J Gastrointest Surg 2006;10:813-822.

16. Brozzetti S, Mazzoni G, Miccini M, et al. Surgical treatment of pancreatic head carcinoma in elderly patients. Arch Surg 2006;141:137-142.

17. DiCarlo V, Balzano G, Zerbi A, Villa E. Pancreatic cancer resection in elderly patients. Br J Surg 1998;85:607-610.

18. Vickers SM, Kerby JD, Smoot TM, et al. Economics of pancreatoduodenectomy in the elderly. Surgery 1996;120:620-626.

19. Fong Y, Blumgart LH, Fortner JG, Brennan MF. Pancreatic or liver resection for malignancy is safe and effective for the elderly. Ann Surg 1995:222:426-437.

20. Siegel RL, Miller KD, Jemal A. Cancer statistics, 2015. CA Cancer J Clin 2015;65:5-29.

21. Yancik R, Ries LA. Cancer in older persons: an international issue in an aging world. Semin Oncol 2004;31:128-136.

22. Howlader N, Noone AM, Krapcho M, et al. SEER cancer statistics review, 1975-2009 (vintage 2009 populations) [Internet]. Bethesda (MD): National Cancer Institute; updated 2012 Aug 20 [cited 2011 Nov]. Available from: https://seer.cancer.gov/archive/csr/1975_2009_ pops09\%.

23. Bouchardy C, Rapiti E, Blagojevic S, Vlastos AT, Vlastos G. Older female cancer patients: importance, causes, and consequences of undertreatment. J Clin Oncol 2007;25:1858-1869.

24. Quaglia A, Tavilla A, Shack L, et al. The cancer survival gap between elderly and middle-aged patients in Europe is widening. Eur J Cancer 2009:45:1006-1016

25. Parmar AD, Vargas GM, Tamirisa NP, Sheffield KM, Riall TS. Trajectory of care and use of multimodality therapy in older patients with pancreatic adenocarcinoma. Surgery 2014;156:280-289.

26. Shiozawa $S$, Usui $T$, Kuhara K, et al. Eligibility criteria specific to pancreaticoduodenectomy for octogenarians: single-center opinion. Anticancer Res 2017;37:2037-2043.

27. Casadei R, Zanini N, Morselli-Labate AM, et al. Prognostic factors in periampullary and pancreatic tumor resection in elderly patients. World J Surg 2006;30:1992-2003.

28. Kang CM, Kim JY, Choi GH, et al. Pancreaticoduodenectomy of pancreatic ductal adenocarcinoma in the elderly. Yonsei Med J 2007;48:488-494.

29. Gerstenhaber F, Grossman J, Lubezky N, et al. Pancreaticoduodenectomy in elderly adults: is it justified in terms of mortality, long-term morbidity, and quality of life?. J Am Geriatr Soc 2013;61:1351-1357.

30. Kim SY, Fink MA, Perini $M$, et al. Age 80 years and over is not associated with increased morbidity and mortality following pancreaticoduodenectomy. ANZ J Surg 2018;88:E445-E450.

31. Casadei R, Taffurelli G, Silvestri S, Ricci C, Campra D, Minni F. Is age a barrier to pancreaticoduodenectomy? An Italian dual-institution study. Updates Surg 2015;67:439-447.

32. Kang JS, Kim H, Kim JR, et al. Short- and long-term outcomes of pancreaticoduodenectomy in elderly patients with periampullary cancer. Ann Surg Treat Res 2020;98:7-14.

33. Chen JW, Shyr YM, Su CH, Wu CW, Lui WY. Is pancreaticoduodenectomy justified for septuagenarians and octogenarians?. Hepatogastroenterology 2003;50:1661-1664.

34. Makary MA, Winter JM, Cameron JL, et al. Pancreaticoduodenectomy in the very elderly. J Gastrointest Surg 2006;10:347-356.

35. Melis M, Marcon F, Masi A, et al. The safety of a pancreaticoduodenectomy in patients older than 80 years: risk vs. benefits. HPB (Oxford) 2012;14:583-588.

36. Kim SY, Weinberg L, Christophi C, Nikfarjam M. The outcomes of pancreaticoduodenectomy in patients aged 80 or older: a systematic review and meta-analysis. HPB (Oxford) 2017;19:475-482.

37. Gagner M, Pomp A. Laparoscopic pylorus-preserving pancreatoduodenectomy. Surg Endosc 1994;8:408-410.

38. Hogg ME, Besselink MG, Clavien PA, et al. Training in minimally invasive pancreatic resections: a paradigm shift away from "See one, do one, teach one". HPB (Oxford) 2017;19:234-245.

39. Tee MC, Croome KP, Shubert CR, et al. Laparoscopic pancreatoduodenectomy does not completely mitigate increased perioperative risks in elderly patients. HPB (Oxford) 2015;17:909-918.

40. Zhou J, Xin C, Xia T, et al. Laparoscopic pancreaticoduodenectomy in a-92-older Chinese patient for cancer of head of the pancreas: a case report. Medicine (Baltimore) 2017;96:e5962.

41. Croome KP, Farnell MB, Que FG, et al. Total laparoscopic pancreaticoduodenectomy for pancreatic ductal adenocarcinoma: oncologic advantages over open approaches?. Ann Surg 2014;260:633-640.

42. Asbun HJ, Stauffer JA. Laparoscopic vs open pancreaticoduodenec- 
tomy: overall outcomes and severity of complications using the Accordion Severity Grading System. J Am Coll Surg 2012;215:810-819.

43. Winter JM, Cameron JL, Campbell KA, et al. 1423 pancreaticoduodenectomies for pancreatic cancer: a single-institution experience. J Gastrointest Surg 2006;10:1199-1211.

44. Tani M, Kawai M, Hirono S, et al. A pancreaticoduodenectomy is acceptable for periampullary tumors in the elderly, even in patients over 80 years of age. J Hepatobiliary Pancreat Surg 2009;16:675-680.

45. Jin W, Xu X, Mou Y, et al. Early experience of laparoscopic pancreaticoduodenectomy on 66 cases. Zhonghua Wai Ke Za Zhi 2016;54:8488.

46. Hatzaras I, Schmidt C, Klemanski D, et al. Pancreatic resection in the octogenarian: a safe option for pancreatic malignancy. J Am Coll Surg 2011;212:373-377.

47. Wiltberger $G$, Muhl B, Benzing C, Hau HM, Bartels M, Krenzien F. Pancreaticoduodenectomy in the elderly patient: age-adapted risk assessment. Dig Surg 2017;34:43-51.
48. Ansari D, Aronsson L, Fredriksson J, Andersson B, Andersson R. Safety of pancreatic resection in the elderly: a retrospective analysis of 556 patients. Ann Gastroenterol 2016;29:221-225.

49. Buchs NC, Addeo P, Bianco FM, Gangemi A, Ayloo SM, Giulianotti PC. Outcomes of robot-assisted pancreaticoduodenectomy in patients older than 70 years: a comparative study. World J Surg 2010;34:21092114.

50. Beltrame V, Gruppo M, Pastorelli D, Pedrazzoli S, Merigliano S, Sperti C. Outcome of pancreaticoduodenectomy in octogenarians: single institution's experience and review of the literature. J Visc Surg 2015;152:279-284.

51. Yamashita Y, Shirabe K, Tsujita E, et al. Surgical outcomes of pancreaticoduodenectomy for periampullary tumors in elderly patients. Langenbecks Arch Surg 2013;398:539-545.

52. Hendi M, Mou Y, Lu C, et al. Laparoscopic pancreaticodoudenectomy: an excellent approach in elderly patients, a multicenter, comparative study. Medicine (Baltimore) 2020;99:e22175. 